\title{
Winning images from the Photography in Medical Physics (PiMP) competition
}

๑) Australasian College of Physical Scientists and Engineers in Medicine 2020

“MicroBeam crossfire”, (C) Duncan Butler (Australian Radiation and Nuclear Safety Agency)

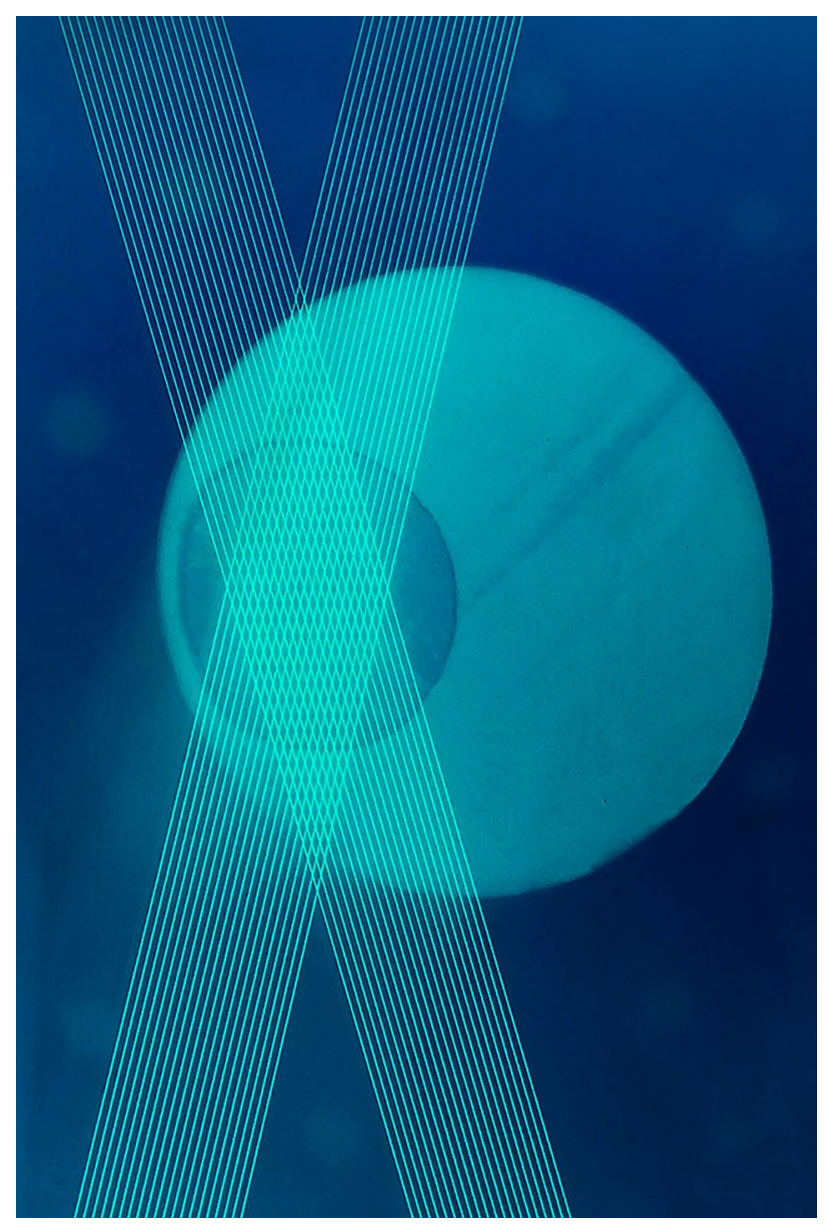

Winning images from the Photography in Medical Physics (PiMP) competition

http://photographyinmedicalphysics.com/

https://www.facebook.com/go4PIMP/

Joerg Lehmann (University of Sydney); May Whitaker (Chris O'Brien Lifehouse); and Alannah Kejda (Blacktown Hospital); Hans from Gamma Gurus.
Winners are judged by a jury of professionals from Medical Physics and Photography, and also by People's choice (members of the ACPSEM).

Publisher's Note Springer Nature remains neutral with regard to jurisdictional claims in published maps and institutional affiliations. 